\title{
Chapter \\ An Approach to the \\ Bleeding Child
}

Shoshana Revel-Vilk

Margaret L. Rand

Sara J. Israels

\section{Introduction}

Bleeding in a child can be a diagnostic challenge because of the wide range of possible causes, but making a specific diagnosis is clinically important in order to provide appropriate therapy. An excessive bleeding response to commonly encountered challenges suggests the possibility of an underlying bleeding disorder. Symptoms such as bruising and epistaxis occur frequently in children without underlying bleeding disorders, and so determining which child requires further investigation can be difficult. Even when initial symptoms appear unimpressive, children with underlying bleeding disorders may be at increased risk for significant bleeding associated with surgical procedures or trauma.

Bleeding disorders can be inherited or acquired, and include coagulation factor deficiencies, platelet deficiencies and/or dysfunctions, and VWD $[1,2]$.The evaluation of a child presenting with bleeding should include a comprehensive medical and bleeding history, a complete family history, a detailed physical examination and selected laboratory tests as outlined in algorithm 1 .

\section{History}

\section{Medical History}

Clinical evaluation of a bleeding patient begins with a detailed history, with emphasis on the child's age, sex, past medical history, clinical presentation, and family history.

\section{Age}

Most cases of severe inherited hemostatic defects will be diagnosed in infancy because of significant mucocutaneous bleeding, postcircumcision bleeding, bleeding from the umbilical stump or ICH. However, moderate and mild inherited hemostatic defects may not present with clinical bleeding until an older age, or until the child is exposed to a hemostatic challenge. Thus, the possibility of an inherited hemostatic defect should 
Table 1. Clinical abnormalities associated with inherited bleeding disorders

\begin{tabular}{|c|c|}
\hline \multicolumn{2}{|l|}{ Coagulation defects } \\
\hline FXIII deficiency & poor wound healing, severe scar formation \\
\hline \multicolumn{2}{|l|}{ Platelet function defects } \\
\hline Hermansky-Pudlak syndrome & oculocutaneous albinism \\
\hline Chediak-Higashi syndrome & $\begin{array}{l}\text { oculocutaneous albinism, infections, neutrophil } \\
\text { peroxidase-positive inclusions }\end{array}$ \\
\hline ARC syndrome & arthrogryposis, renal dysfunction, cholestasis \\
\hline MYH9-related disorders & cataracts, sensorineural hearing defect, nephritis \\
\hline Leukocyte adhesion deficiency type III & $\begin{array}{l}\text { recurrent severe infections, delayed separation of the umbilical } \\
\text { cord, neutrophilia }\end{array}$ \\
\hline \multicolumn{2}{|l|}{ Thrombocytopenia } \\
\hline Wiskott-Aldrich syndrome & eczema, immunodeficiency \\
\hline $\begin{array}{l}\text { Thrombocytopenia with absent radii, amegakaryocytic } \\
\text { thrombocytopenia with radioulnar synostosis }\end{array}$ & skeletal defects \\
\hline DiGeorge/velocardiofacial syndrome & cleft palate, cardiac defects, facial anomalies, learning disabilities \\
\hline Paris-Trousseau/Jacobsen syndrome & cardiac defects, craniofacial anomalies, mental retardation \\
\hline $\begin{array}{l}\text { X-linked thrombocytopenia and dyserythropoiesis with or } \\
\text { without anemia/X-linked thrombocytopenia-thalassemia }\end{array}$ & $\begin{array}{l}\text { microcytosis of red blood cells, unbalanced hemoglobin chain } \\
\text { synthesis resembling } \beta \text {-thalassemia minor }\end{array}$ \\
\hline
\end{tabular}

be considered in a child with clinically significant bleeding symptoms/signs, regardless of the age at presentation.

Acquired bleeding disorders can present at any age. For example, although ITP commonly presents between the ages of 2-10 years, presentation from the age of 3 months until adulthood can occur.

\section{Sex}

Some of the inherited hemostatic defects such as hemophilia A (FVIII deficiency), hemophilia B (FIX deficiency), Wiskott-Aldrich syndrome/Xlinked thrombocytopenia, and X-linked thrombocytopenia with dyserythropoiesis are due to mutations on the $\mathrm{X}$ chromosome. A family history of bleeding limited to males suggests an X-linked disorder. All other inherited and acquired hemostatic defects occurs in both sexes, although there is an elevated rate of diagnosis of VWD, platelet defects and FXI deficiency in women because of menorrhagia [3].

\section{General Medical History}

Presentation of signs and symptoms other than bleeding can provide a clue to the diagnosis of inherited hemostatic disorders (table 1). A detailed medical history is essential for the diagnosis of acquired hemostatic disorders. A history of weakness, fever, weight loss, etc., can suggest malignancy. Liver disease affects synthesis of multiple coagulation factors. Cholestasis, fat malabsorption or antibiotic use can cause vitamin $\mathrm{K}$ deficiency. Sepsis is associated with consumptive coagulopathy and thrombocytopenia. Uremia can be associated with acquired platelet dysfunction. The use of medications can be associated with drug-induced thrombocytopenia, or platelet dysfunction (chapter 5).

\section{Bleeding History}

Type and pattern of bleeding are important indicators of possible diagnoses. Mucocutaneous bleeding such as petechiae, bruising, epistaxis, gastrointestinal bleeding and/or menorrhagia suggests disorders of platelets, VWD, or the 
vasculature. There may be prolonged bleeding following surgery and/or dental extractions. In contrast, spontaneous or excessive bleeding into soft tissues, muscles and joints, or delayed surgical bleeding suggests disorders of coagulation factors. It should be noted that coagulation factor disorders may also cause mucocutaneous bleeding, epistaxis, or gastrointestinal bleeding. $\mathrm{ICH}$, postcircumcision bleeding or severe mucosal bleeding in early infancy requires immediate investigation for a coagulation factor deficiency. Bleeding from the umbilical cord stump within the first days of life is strongly suggestive of FXIII deficiency or afibrinogenemia.

The onset and acuity of bleeding can also aid in indicating a specific diagnosis. Acquired disorders may have an acute onset (e.g. ITP) compared with inherited disorders where symptoms are present for months or years. Challenges to the hemostatic system are often required to make a bleeding disorder clinically evident, so that mild/ moderate bleeding disorders may not be appreciated until events such as trauma, surgery, or menarche occur.

The recognition of significant clinical bleeding is the first step in the diagnosis of bleeding disorders [4]. In children with severe bleeding disorders, the bleeding history is usually clear. However, children presenting with mild/moderate bleeding symptoms may have bleeding symptoms such as recurrent epistaxis or bruises that are also common among healthy children. The distinction between normal children and those with bleeding disorders can be difficult to make.

The use of standardized scores to quantitate bleeding symptoms is recommended. Recently, a PBQ (an adaptation of the standardized MCM DM-1 VWD questionnaire), was developed and validated (table 2) [5-7]. It provides a summative score for 13 bleeding symptoms: epistaxis, cutaneous bleeding, bleeding from minor wounds, oral cavity bleeding, gastrointestinal bleeding, bleeding post-tooth extraction, postsurgical bleeding, menorrhagia, postpartum hemorrhage, muscle hematoma, hemarthrosis, central nervous system bleeding and 'other', pediatric-specific bleeding symptoms (postcircumcision bleeding, umbilical stump bleeding, cephalohematoma, macroscopic hematuria, postvenipuncture bleeding, conjunctival hemorrhage). The mean bleeding score in healthy children was 0.5 , and a bleeding score of $\geq 2$ was defined as abnormal. The PBQ was validated prospectively as a screening tool for the diagnosis of VWD and studies validating it for the diagnosis of other bleeding disorders are ongoing.

\section{Family History}

In addition to the child's bleeding history, the family history may provide important clues about the potential inheritance of an underlying bleeding disorder. For example, an autosomaldominant inheritance pattern would be in keeping with type $1 \mathrm{VWD}$ and some platelet function disorders, and a sex-linked pattern, with FVIII or FIX deficiency. Consanguinity in a family increases the risk of autosomal-recessive disorders. Evaluation of the bleeding history in family members by a validated bleeding questionnaire could be useful for appreciating the significance of the family bleeding history.

Generally, there is little racial or ethnic predisposition to bleeding disorders. However, there are some bleeding disorders which are more prevalent in certain populations, e.g. FXI deficiency among Jews of Ashkenazi (European) origin and among the Basque population of south-western France and north-eastern Spain. Autosomal-recessive bleeding disorders can be more common in small, geographically or ethnically isolated communities sharing common genes.

\section{Physical Examination}

A careful physical examination for evaluation of clinical bleeding and associated abnormalities is an essential part in the diagnosis of hemostatic 
Table 2. Pediatric bleeding questionnaire scoring key

\begin{tabular}{|c|c|c|c|c|c|c|}
\hline Symptom & -1 & 0 & 1 & 2 & 3 & 4 \\
\hline Epistaxis & - & $\begin{array}{l}\text { no or trivial } \\
\text { ( } \leq 5 \text { per year) }\end{array}$ & $\begin{array}{l}>5 \text { per year or } \\
>10 \text { min duration }\end{array}$ & consultation only & $\begin{array}{l}\text { packing, cauterization or } \\
\text { antifibrinolytics }\end{array}$ & $\begin{array}{l}\text { blood transfusion, replacement } \\
\text { therapy or desmopressin }\end{array}$ \\
\hline Cutaneous & - & $\begin{array}{l}\text { no or trivial } \\
(\leq 1 \mathrm{~cm})\end{array}$ & $\begin{array}{l}>1 \mathrm{~cm} \text { and } \\
\text { no trauma }\end{array}$ & consultation only & - & - \\
\hline Minor wounds & - & $\begin{array}{l}\text { no or trivial } \\
\text { ( } \leq 5 \text { per year) }\end{array}$ & $\begin{array}{l}>5 \text { per year or } \\
>5 \text { min duration }\end{array}$ & $\begin{array}{l}\text { consultation only or } \\
\text { steri-strips }\end{array}$ & $\begin{array}{l}\text { surgical hemostasis or } \\
\text { antifibrinolytics }\end{array}$ & $\begin{array}{l}\text { blood transfusion, replacement } \\
\text { therapy or desmopressin }\end{array}$ \\
\hline Oral cavity & - & no & $\begin{array}{l}\text { reported at } \\
\text { least one }\end{array}$ & consultation only & $\begin{array}{l}\text { surgical hemostasis or } \\
\text { antifibrinolytics }\end{array}$ & $\begin{array}{l}\text { blood transfusion, replacement } \\
\text { therapy or desmopressin }\end{array}$ \\
\hline $\begin{array}{l}\text { Gastrointestinal } \\
\text { tract }\end{array}$ & - & no & identified cause & $\begin{array}{l}\text { consultation or } \\
\text { spontaneous }\end{array}$ & $\begin{array}{l}\text { surgical hemostasis, } \\
\text { antifibrinolytics, } \\
\text { blood transfusion, } \\
\text { replacement therapy or } \\
\text { desmopressin }\end{array}$ & - \\
\hline Tooth extraction & $\begin{array}{l}\text { no bleeding } \\
\text { in at least } \\
2 \text { extractions }\end{array}$ & $\begin{array}{l}\text { none done } \\
\text { or no bleeding } \\
\text { in } 1\end{array}$ & $\begin{array}{l}\text { reported, no } \\
\text { consultation }\end{array}$ & consultation only & $\begin{array}{l}\text { resuturing, repacking or } \\
\text { antifibrinolytics }\end{array}$ & $\begin{array}{l}\text { blood transfusion, replacement } \\
\text { therapy or desmopressin }\end{array}$ \\
\hline Surgery & $\begin{array}{l}\text { no bleeding } \\
\text { in at least } \\
2 \text { surgeries }\end{array}$ & $\begin{array}{l}\text { none done } \\
\text { or no bleeding } \\
\text { in } 1\end{array}$ & $\begin{array}{l}\text { reported, no } \\
\text { consultation }\end{array}$ & consultation only & $\begin{array}{l}\text { surgical hemostasis or } \\
\text { antifibrinolytics }\end{array}$ & $\begin{array}{l}\text { blood transfusion, replacement } \\
\text { therapy or desmopressin }\end{array}$ \\
\hline Menorrhagia & - & no & $\begin{array}{l}\text { reported or } \\
\text { consultation only }\end{array}$ & $\begin{array}{l}\text { antifibrinolytics or } \\
\text { contraceptive pill use }\end{array}$ & $D \& C$ or iron therapy & $\begin{array}{l}\text { blood transfusion, replacement } \\
\text { therapy, desmopressin or } \\
\text { hysterectomy }\end{array}$ \\
\hline Postpartum & $\begin{array}{l}\text { no bleeding } \\
\text { in at least } \\
2 \text { deliveries }\end{array}$ & $\begin{array}{l}\text { no deliveries } \\
\text { or no bleeding } \\
\text { in } 1 \text { delivery }\end{array}$ & $\begin{array}{l}\text { reported or } \\
\text { consultation only }\end{array}$ & $\begin{array}{l}\text { D\&C, iron therapy or } \\
\text { antifibrinolytics }\end{array}$ & $\begin{array}{l}\text { blood transfusion, } \\
\text { replacement therapy or } \\
\text { desmopressin }\end{array}$ & - \\
\hline Muscle hematoma & - & never & $\begin{array}{l}\text { post-trauma, } \\
\text { no therapy }\end{array}$ & $\begin{array}{l}\text { spontaneous, no } \\
\text { therapy }\end{array}$ & $\begin{array}{l}\text { spontaneous or } \\
\text { traumatic, requiring } \\
\text { desmopressin or } \\
\text { replacement therapy }\end{array}$ & $\begin{array}{l}\text { spontaneous or traumatic, } \\
\text { requiring surgical intervention or } \\
\text { blood transfusion }\end{array}$ \\
\hline Hemarthrosis & - & never & $\begin{array}{l}\text { post-trauma, } \\
\text { no therapy }\end{array}$ & $\begin{array}{l}\text { spontaneous, no } \\
\text { therapy }\end{array}$ & $\begin{array}{l}\text { spontaneous or } \\
\text { traumatic, requiring } \\
\text { desmopressin or } \\
\text { replacement therapy }\end{array}$ & $\begin{array}{l}\text { spontaneous or traumatic, } \\
\text { requiring surgical intervention or } \\
\text { blood transfusion }\end{array}$ \\
\hline $\begin{array}{l}\text { Central nervous } \\
\text { system }\end{array}$ & - & never & - & - & $\begin{array}{l}\text { subdural, any } \\
\text { intervention }\end{array}$ & intracerebral, any intervention \\
\hline $\begin{array}{l}\text { Other: } \\
\text { postcircumcision } \\
\text { umbilical stump } \\
\text { cephalohematoma } \\
\text { macroscopic } \\
\quad \text { hematuria } \\
\text { postvenipuncture } \\
\text { conjunctival } \\
\text { hemorrhage }\end{array}$ & - & no & reported & consultation only & $\begin{array}{l}\text { surgical hemostasis, } \\
\text { antifibrinolytics or iron } \\
\text { therapy }\end{array}$ & $\begin{array}{l}\text { blood transfusion, replacement } \\
\text { therapy or desmopressin }\end{array}$ \\
\hline
\end{tabular}


disorders. Mucocutaneous bleeding suggests a disorder of primary hemostasis, i.e. VWD or platelet dysfunction/deficiency, or a vascular disorder. In males, deep hematomas, hemarthroses, or evidence of chronic joint abnormalities suggests hemophilia. Acquired bleeding disorders may present in the context of coexisting illness. Lymphadenopathy and/or organomegaly suggest an infiltrative process such as malignancy or a storage disease. Signs of liver failure suggest acquired coagulation factor deficiencies. Additional congenital anomalies may suggest the presence of a syndromic bleeding disorder (table 1).

A pattern of bruising that is not consistent with accidental injury should raise the concern about nonaccidental trauma.

\section{Laboratory Investigations}

Laboratory screening tests for suspected bleeding disorders provide additional diagnostic indicators that direct more specific investigations. Algorithm 1 provides an approach to evaluation of a child with bleeding symptoms.

\section{Screening Tests}

Initial tests to screen for bleeding disorders should include a CBC, blood film, PT and aPTT.

$C B C$ (blood collected into EDTA) is performed to exclude thrombocytopenia. It should be noted, however, that automated cell counters (counters based on impedance rather than optical technology) may underestimate platelet counts and under- or overestimate mean platelet volume when platelet size is outside of the established reference interval. The $\mathrm{CBC}$ also provides information about additional cytopenias, and other WBC and RBC abnormalities.

Peripheral blood film (blood collected into EDTA) provides additional information regarding platelet number, size, clumping and granularity (the platelet count can be estimated by the number of platelets per $\times 100$ field multiplied by $\left.20 \times 10^{9} / 1\right)$. Pseudothrombocytopenia resulting from clumping of platelets collected in EDTA anticoagulant can be identified by examination of the blood film, and confirmed by re-collecting a specimen in citrate anticoagulant in which clumping will not occur. Examination of the peripheral blood film is essential in the evaluation of a child with a suspected platelet disorder (chapter 5). If true thrombocytopenia is diagnosed, the next step would be to differentiate between new onset acquired thrombocytopenia, chronic acquired thrombocytopenia and congenital thrombocytopenia (algorithm 1; chapter 5).

Evaluation of WBC morphology allows identification of malignant blasts, granulocyte inclusions, such as Döhle like bodies, or other WBC abnormities. Evaluation of RBC morphology is important to exclude a microangiopathic process as evidenced by presence of fragmented red blood cells, microcytosis, macrocytosis and other RBC abnormalities.

PT/INR (blood collected into citrate) measures the extrinsic and common pathway in the coagulation cascade (tissue factor, FVII, FX, FV, FII, fibrinogen). Results should be compared with agespecific laboratory reference intervals (Appendix), and are reported in seconds and/or as a percentage of a normal control sample. The INR is the ratio of a patient's PT to a normal control sample, raised to the power of the ISI value for the analytical system used: (observed PT/control PT) ${ }^{\mathrm{ISI}}$, where ISI = international sensitivity index (sensitivity of thromboplastin). The INR was developed for guiding management in patients treated with oral VKA and was not meant to be used for evaluation of bleeding. However, as some laboratories now report only the INR, it has been included in algorithm 1. A prolonged PT/high INR (with normal aPTT) suggests FVII deficiency, or use of VKA such as warfarin.

Algorithm 1. Evaluation of a child presenting with bleeding symptoms. 


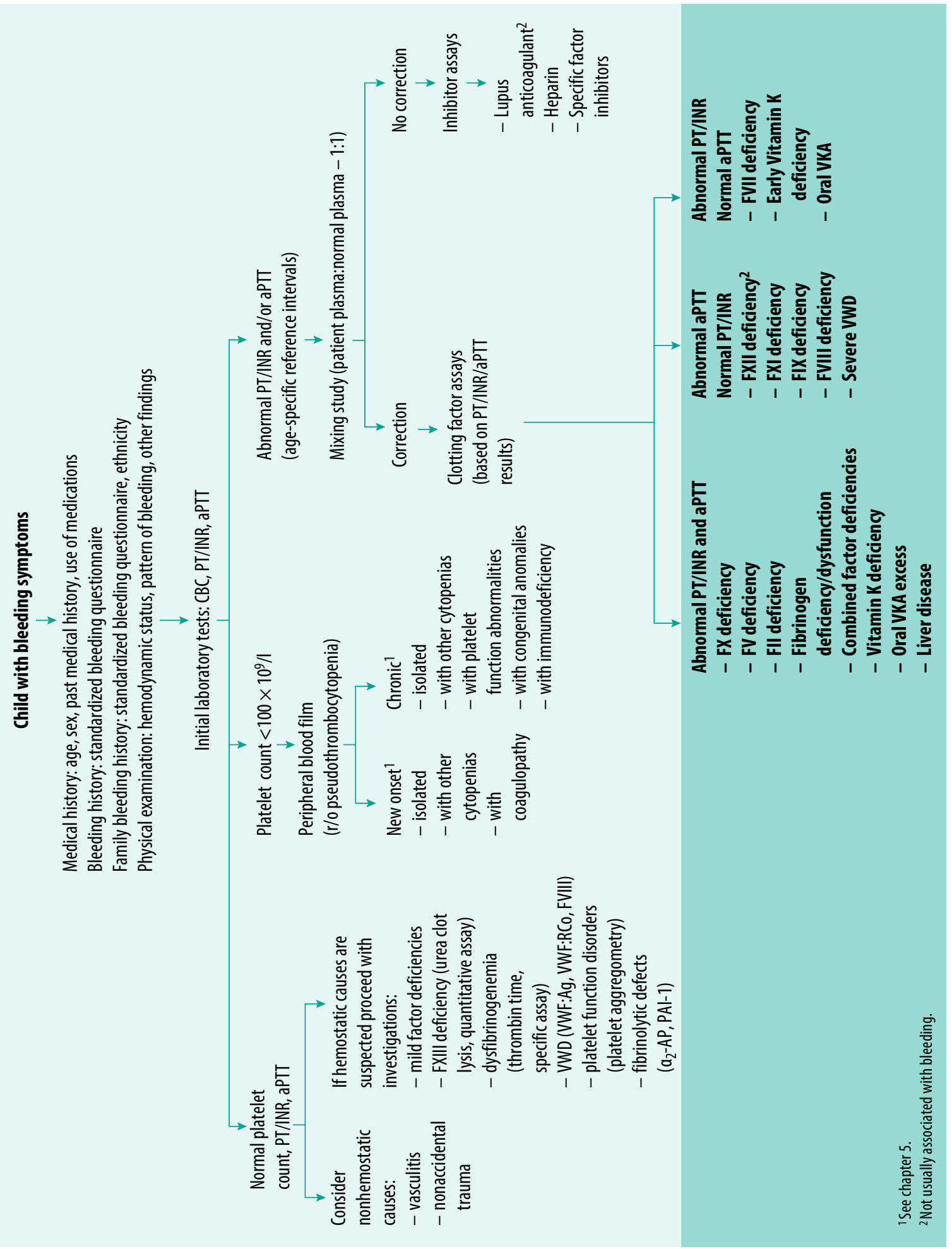


aPTT (blood collected into citrate) measures the intrinsic and common pathways of coagulation (FXII, FXI, FIX, FVIII, FX, FV, FII, fibrinogen). The aPTT is less sensitive than the PT to deficiencies of the common pathway factors. Results should be compared with age-specific laboratory reference intervals (Appendix), and results are reported in seconds. An abnormally prolonged aPTT (with normal PT/INR) suggests FVIII or FIX deficiency (chapter 6) and FXI deficiency (chapter 8). Importantly, an aPTT within the reference range does not reliably exclude mild FVIII, FIX or FXI deficiency. Therefore, factor assays should be performed if specific deficiencies are suspected. FXII deficiency also causes a prolonged aPTT, but is not associated with clinical bleeding. A prolonged aPTT can occur in severe VWD, as a result of the associated FVIII deficiency (chapter 7).

The aPTT is also prolonged in the presence of inhibitors including heparin. Heparin contamination occurs most often in specimens drawn from arterial or central venous catheters. To avoid heparin contamination, an adequate volume of blood should be removed prior to sampling (chapter 16). Where that is not possible, heparin neutralization can be performed, usually by the addition of heparinase to the sample plasma.

Combined prolongation of PT/INR and aPTT can result from inherited deficiencies of individual factors in the common pathway: FX, FV, FII and fibrinogen, or from the rare inherited deficiency of the vitamin K-dependent coagulation factors (chapter 8). More commonly, combined abnormalities of aPTT and PT/INR are the result of acquired deficiencies of multiple coagulation factors (chapter 9).

A mixing study (patient plasma 1:1 normal plasma) (blood collected into citrate) is done when an abnormal PT and/or an aPTT is identified. The patient's plasma is mixed with normal plasma in a 1:1 ratio, and the screening tests are repeated. This test differentiates between factor deficiency (mixing corrects the PT or aPTT) and the presence of an inhibitor (mixing does not correct the
PT or aPTT). The most common inhibitor that results in noncorrection of the aPTT with mixing is a lupus anticoagulant. This is often an incidental finding in children and is not associated with clinical bleeding. Specialized assays will confirm its presence. Specific factor inhibitors also interfere with correction of screening tests by mixing with normal plasma. Confirmation requires specific inhibitor assays (chapter 9).

PT and aPTT reagents used for testing have variable sensitivities to coagulation factors and insensitive reagents may result in false negative (i.e. normal) results for mild deficiencies. If there is a strong suspicion of a coagulation factor deficiency, specific factor assays should be performed.

TT and fibrinogen measurement (blood collected into citrate): TT measures the thrombin-induced conversion of fibrinogen to fibrin. A prolonged TT suggests a quantitative or qualitative abnormality of fibrinogen or the presence of heparin in the sample. A quantitative measurement of fibrinogen should also be performed.

PT, aPTT, and TT do not screen for factor XIII deficiency.

Urea clot lysis test (blood collected into citrate) measures the solubility of the clot with the addition of urea. An abnormal test suggests severe FXIII deficiency or hypofibrinogenemia. Clot solubility is increased only at very low levels of FXIII levels $(<3 \%)$ and therefore does not detect mild/moderate deficiencies. A quantitative assay of FXIII should be used to confirm the result of this screening test (chapter 8).

Bleeding time (using a device appropriate for size of child): a lancet device is used to make a standardized cut on the volar surface of the forearm, and the time it takes for bleeding to stop is measured. The bleeding time test was widely used as a screening test for primary hemostasis disorders, but is less often used now because of difficulties in standardization.

Platelet function analyzer, $P F A-100^{\circledR}$ (blood collected into citrate) is an instrument in which primary, platelet-related hemostasis is simulated. 
A small sample of anticoagulated whole blood $(0.8 \mathrm{ml})$ is aspirated via a narrow-diameter capillary through a microscopic aperture cut into a membrane coated with the platelet agonists collagen and epinephrine or collagen and adenosine $5^{\prime}$-diphosphate. The high shear rate generated under the standardized flow conditions and presence of the chemical stimuli result in platelet adhesion, activation and aggregation at the aperture, building a stable platelet plug. The time required to obtain full occlusion of the aperture is reported as the closure time. The closure time is prolonged by low levels of VWF, thrombocytopenia, decreased hematocrit, and by some platelet function abnormalities (e.g. severe disorders such as Bernard-Soulier syndrome and Glanzmann thrombasthenia). Due to issues of both sensitivity and specificity, use of the PFA- $100{ }^{\circledR}$ as a routine screening test is still debated. However, the small blood volume needed for this test compared with the much larger volume required for platelet function testing by aggregometry (10 $\mathrm{ml}$ or more) is an advantage, especially for screening very young children for VWD or severe platelet function disorders.

\section{Testing for Defects in Primary Hemostasis}

VWF antigen and activity (ristocetin cofactor assay) (blood collected into citrate): these tests measure the level and the activity of VWF for the diagnosis of VWD. Specialized laboratory evaluations of VWF to determine VWD subtype are discussed in chapter 7 .

Platelet function testing (blood collected into citrate): the most common method of assessing platelet function is light transmission aggregometry, in which the increase in light transmission through a rapidly stirred sample of citrated platelet-rich plasma as recorded as platelets aggregate (chapter 5). As a fresh blood sample is needed for aggregation testing, the patient may have to be referred to a center with a specialized laboratory [8]. Specialized testing including measurement of granule secretion, dense granule enumeration by whole mount electron microscopy, flow cytometric assessment of surface receptors and evaluation of platelet ultrastructure by transmission electron microscopy are discussed in chapter 5 .

\section{Fibrinolysis Inhibitors}

Abnormalities of fibrinolysis inhibitors (blood collected into citrate), such as $\alpha_{2}$-AP and PAI- 1 , can cause rare bleeding disorders because of increased fibrinolysis [9].

\section{Genetic Testing}

The genetic mutations associated with inherited hemostatic disorders are gradually being revealed. If available, mutational analysis aids in accurate diagnosis and improves genetic counseling and prenatal diagnosis. Recommendations for genetic testing for specific disorders are provided in the relevant chapters.

\section{References}

1 Carcao MD, Blanchette VS: Work-up of a bleeding child; in Lee C, Berntorp E, Hoots K (eds): Textbook of Hemophilia, ed 2. London, Blackwell, 2010, p 118.

2 Revel-Vilk S: Clinical and laboratory assessment of the bleeding pediatric patient. Semin Thromb Hemost 2011;37:756.

3 James AH, Kouides PA, Abdul-Kadir R, Dietrich JE, Edlund M, Federici AB, Halimeh S, Kamphuisen PW, Lee CA, Martinez-Perez O, McLintock C, Peyvandi F, Philipp C, Wilkinson J, Winikoff R: Evaluation and management of acute menorrhagia in women with and without underlying bleeding disorders: consensus from an international expert panel. Eur J Obstet Gynecol Reprod Biol 2011;158:124.

4 Rodeghiero F, Kadir RA, Tosetto A, James PD: Relevance of quantitative assessment of bleeding in haemorrhagic disorders. Haemophilia 2008;14(suppl 3):68.

5 Bowman M, Riddel J, Rand ML, Tosetto A, Silva M, James PD: Evaluation of the diagnostic utility for von Willebrand disease of a pediatric bleeding questionnaire. J Thromb Haemost 2009;7:1418.

-6 Biss TT, Blanchette VS, Clark DS, Bowman M, Wakefield CD, Silva M, Lillicrap D, James PD, Rand ML: Quantitation of bleeding symptoms in children with von Willebrand disease: use of a standardized pediatric bleeding questionnaire. J Thromb Haemost 2010;8:950.

7 Biss TT, Blanchette VS, Clark DS, Wakefield CD, James PD, Rand ML: Use of a quantitative pediatric bleeding questionnaire to assess mucocutaneous bleeding symptoms in children with a platelet function disorder. J Thromb Haemost 2010;8:1416. 
8 Harrison P, Mackie I, Mumford A, Briggs C, Liesner R, Winter M, Machin S: Guidelines for the laboratory investigation of heritable disorders of platelet function. Br J Haematol 2011;155:30.

$\checkmark 9$ Hayward CP: Diagnosis and management of mild bleeding disorders. Hematology Am Soc Hematol Educ Program 2005;2005:423.

\section{Abbreviations}

$\begin{array}{ll}a_{2} \text {-AP } & a_{2} \text {-Antiplasmin } \\ \text { aPTT } & \text { Activated partial thromboplastin time } \\ \text { CBC } & \text { Complete blood count } \\ \text { FII } & \text { Factor II (prothrombin) } \\ \text { FV } & \text { Factor V } \\ \text { FVII } & \text { Factor VII } \\ \text { FVIII } & \text { Factor VIII } \\ \text { FIX } & \text { Factor IX } \\ \text { FX } & \text { Factor X }\end{array}$

Factor XI

Factor XII

Factor XIII

Intracranial hemorrhage

International normalized ratio

$\begin{array}{ll}\text { ITP } & \text { Immune thrombocytopenia } \\ \text { PAI-1 } & \text { Plasminogen activator inhibitor type }\end{array}$

PBQ Pediatric Bleeding Questionnaire

PFA- $1000^{\circledR}$ Platelet function analyzer-100

PT Prothrombin time

RBC Red blood cell

TT Thrombin time

VKA Vitamin K antagonist

VWD von Willebrand disease

VWF von Willebrand factor

VWF:Ag VWF antigen

VWF:RCO VWF activity (ristocetin cofactor assay)

WBC White blood cell 